\title{
Evaluation of thermal properties of insulation systems in pitched roofs
}

\author{
Alexey Zhukov ${ }^{1}$, Armen Ter-Zakaryan ${ }^{2}$, Ekaterina Bobrova ${ }^{3}$, Igor Bessonov ${ }^{4}$, Andrey \\ Medvedev $^{1^{*}}$, Vitaly Mukhametzyanov ${ }^{1}$ and Alexey Poserenin ${ }^{5}$ \\ ${ }^{1}$ Moscow State University of Civil Engineering, 129337, Yaroslavskoye shosse, 26, Moscow, Russia; \\ ${ }^{2}$ LLC TEPOFOL 107140 Krasnoprudnaya str, 12/1 Moscow Russia \\ ${ }^{3}$ Higher School of Economics, 101000, Myasnitskaya str. 20, Moscow, Russia \\ ${ }^{4}$ Scientific-research Institute of building physics, 127238 Lomonososky drive,21 Moscow, Russia \\ ${ }^{5}$ Russian State Geological Prospecting University, 117997, Miklukcho-Maklaya, 23, Moscow, Russia
}

\begin{abstract}
The article outlines the basic requirements for pitched roof insulation systems. The analysis of the properties of thermal insulation materials used in insulation systems was conducted. It is substantiated that the thermal resistance of such structures on the surface of the roof is formed taking into account the thermal conductivity of thermal insulation, thermal conductivity of wooden rafters and heat loss through the leakiness of joints and mounting devices. An assessment was made of the effect of loads of various types on the heat-insulating layer, namely: the effect of the air flow in the ventilated gap; the movement of the vapor-air mixture in the material; condensation of water vapor and penetration of drip liquid; exfiltration of air at the joints of the plates and on the surfaces of contact with the supporting structures. The expediency of using products on the basis of unstitched polyethylene foam in the construction of pitched roofs with a wooden roof system, taking into account the advantages and features of this material, as well as taking into account the possibility of creating a seamless insulating shell, is substantiated.
\end{abstract}

\section{Introduction}

Tasks of roofing systems are protection of a design of a roof and a roof from penetration of moisture and other atmospheric influences, from an overheat of designs and rooms in the hot period, that is minimization of thermal losses, and, consequently, expenses on heating in the cold periods of a year. It is also important to create a comfortable microclimate in the premises and ensure the temperature and humidity conditions of normal operation of the roof structure [1-4].

Mineral wool products, polyurethane foams, plate and roll products on the basis of foamed plastics are used as thermal insulation. In most ways insulation is used in a constructive solution, when insulation is placed between rafters at their full height (Fig. 1a) or with partial filling on height (Fig. 1b). In these systems, it is possible to moisten the thermal insulation layer (first of all, this applies to mineral fiber insulation) both due to

*Corresponding author: medvedev747@yandex.ru 
moisture vapor coming from the room and droplet moisture falling on the insulation as a result of leaks. Therefore, it is necessary to use vapor barrier on the part of the room and waterproofing and wind protection on the part of the roof covering (on the outside of the insulation facing the roof ventilated gap) [5-11].

The effectiveness of the insulation shell is estimated by the thermal resistance of the structure (mainly using computational methods) or by the heat flow through the surface of the roof, determined by the results of experiments [12-15].

\section{Experimental}

The effectiveness of insulation depends on a set of factors. When designing the structure and using the properties stated in the technical documentation, the designer evaluates his decision based on the reliability of the roof structure and the final thermal resistance of the insulation shell, which cannot be less than the standard.

In this case, the standard thermal resistance is determined by the smoothness of the insulated surface, while it is necessary to take into account the heat loss through the mansard glazing, and through various roof sinking (table 1). This thermal resistance can be called project or initial, given that its change can occur over time, taking into account the operating conditions of the roofing system.

The thermal resistance project tends to decrease this implies the need to assess the reliability and durability of the insulation shell.

Table 1. Thermal resistance of roof insulation systems.

\begin{tabular}{|c|l|c|c|}
\hline \multirow{2}{*}{ No } & \multicolumn{1}{|c|}{ Insulation system } & \multicolumn{2}{|c|}{ Thermal resistance, $\mathrm{m}^{2} \cdot{ }^{\circ} \mathrm{C} / \mathrm{W}$} \\
\cline { 3 - 4 } & $\begin{array}{c}\text { On the } \\
\text { roof } \\
\text { surface }\end{array}$ & $\begin{array}{c}\text { Taking into } \\
\text { account } 20 \% \text { of } \\
\text { mansard glazing }\end{array}$ \\
\hline 1 & $\begin{array}{l}\text { Insulation with soft mineral wool slabs for the } \\
\text { entire height of the rafters }\end{array}$ & 4,08 & 1,89 \\
\hline 2 & $\begin{array}{l}\text { Insulation with soft mineral wool slabs at 3/4 of the } \\
\text { height of the rafters }\end{array}$ & 3,59 & 1,80 \\
\hline 3 & Insulation by roll foam polyethylene & 2,93 & 1,65 \\
\hline
\end{tabular}
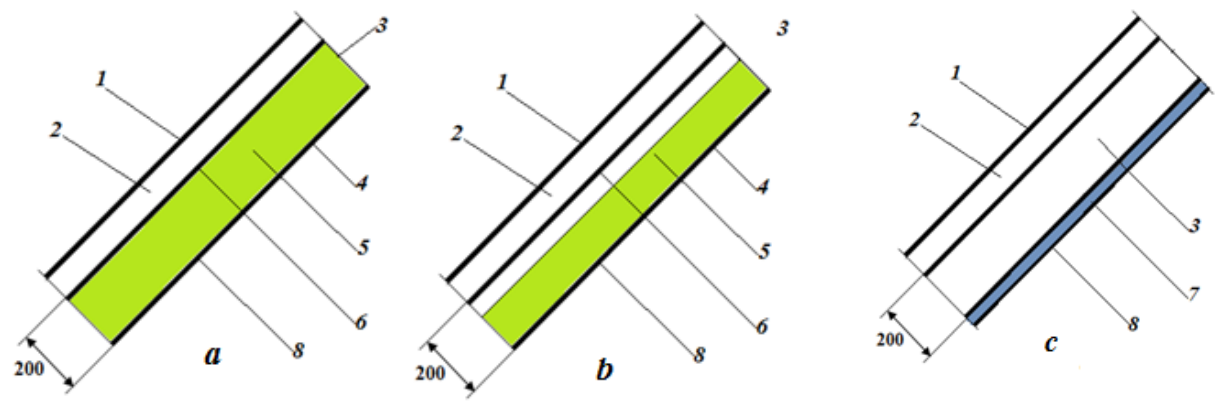

Fig. 1. Construction of the roofing system for insulation of mineral wool slabs for the full height of the rafters (a), $3 / 4$ of the height of the rafters (b) and a rolled foamed polyethylene (c): 1 - roof covering; 2 - ventilated gap; 3 - rafter; 4 - vapor barrier; 5 - heat insulation (mineral wool plates); 6 - windshield; 7 - heat insulation (rolled polyethylene foam); 8 - interior cladding.

The experience of recent years has shown high efficiency of thermal imaging of building structures for determine the heat loss (Fig. 2). According to the results of 
measurements, areas with high and insufficient thermal resistance are clearly expressed. In the considered example these are places of sinking of pipes and roof aerators, as well as roof windows. Researches confirm that it is necessary to take into account the mansard glazing and other structural features of the roofing in assessing the thermal resistance of the shell as a whole. All types of violation of the integrity of the insulation shell cause a change in the thermal resistance project, which confirms the calculation given in the table 1 .

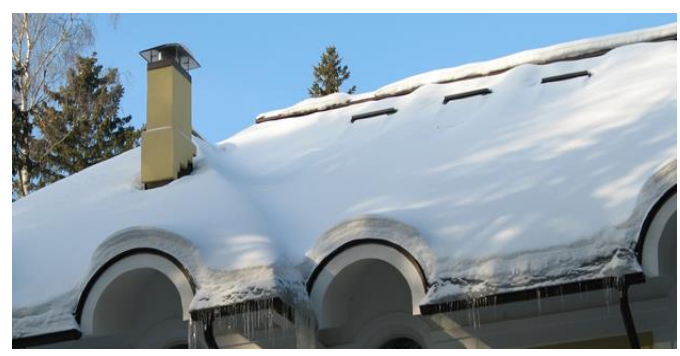

a

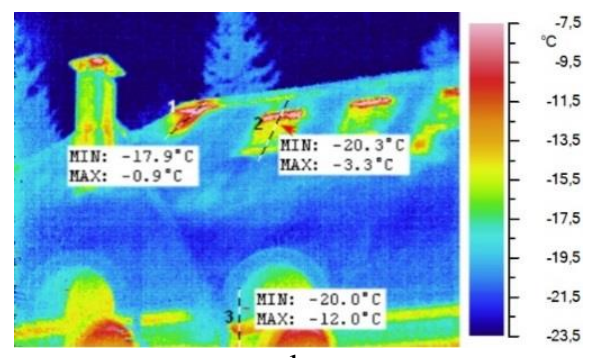

b
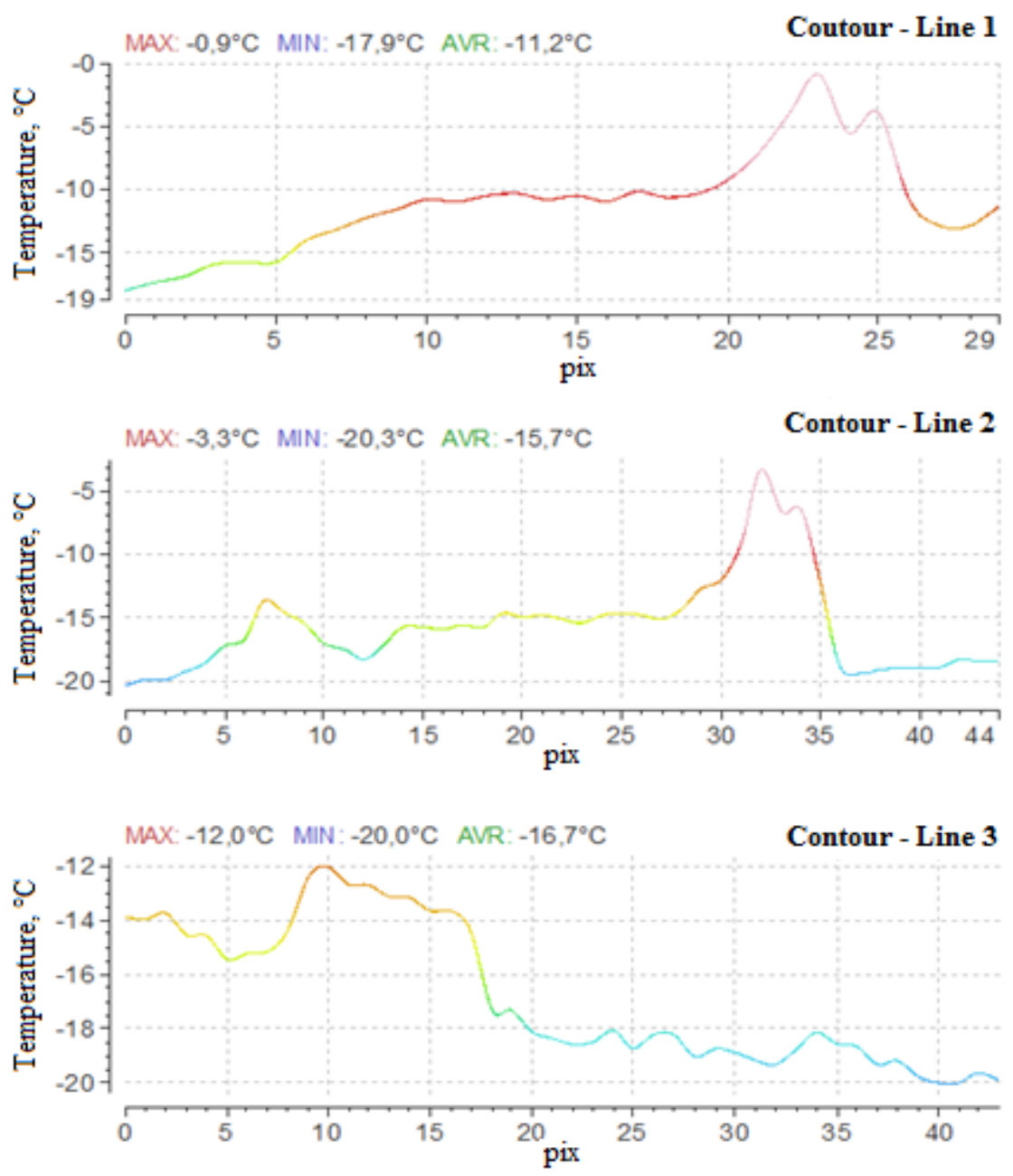

Fig. 2. Evaluation of thermal efficiency of the roof insulation shell: $a$ - General view of the roof; $b-$ thermal imaging results; $\mathrm{c}$ - temperature change in critical areas with low thermal resistance. 
In this survey revealed significant heat loss in the zone "ridge" (section 1), due to "sagging" insulation with loss of thermal properties.

\section{Results}

An important factor affecting the thermal resistance of the structure is the operational resistance of the thermal insulation material. Thermal resistance of insulation depends on the thermal conductivity of the insulation and formability insulation products.

The influence of loads of different types on the heat-insulating layer is estimated, namely: the effect of air flow in the ventilated gap; movement of the steam-air mixture in the material; condensation of water vapor and the penetration of the liquid droplet; exfiltration of air at the joints of plates and on the surfaces adjacent to the supporting structures. It is established that the considered factors inevitably affect the durability of the structure as a whole and cause degradation of the properties of the heat-insulating layer due to geometric deformations, moisture, formation of defects of the insulation shell inevitably reducing the thermal resistance of the insulated structure. Accordingly, the life cycle of the building and the level of comfort in the premises are reduced. In the first place, the conductivity of the products of the insulating sheath depends on moisture content. The main type of thermal insulation is mineral wool products, so these products are paid special attention.

The studies of diffusion moisture absorption of mineral wool plates according to GOST EN 12088 at Peter the Great St. Petersburg Polytechnic University [8] showed the following results presented in the table. 2 .

Table 2. Diffusion moisture absorption of mineral wool plates [8].

\begin{tabular}{|c|c|c|c|c|c|c|}
\hline No & Sample & $\delta, \mathrm{m}$ & $\mathrm{A}, \mathrm{m}^{2}$ & $\mathrm{~m}_{0}, \mathrm{~kg}$ & $\mathrm{~m}_{\mathrm{D}}, \mathrm{g}$ & $\mathrm{W}_{\mathrm{dv}}, \%$ \\
\hline 1 & MW 1 & 0,05 & 0,25 & 1.66 & 3.864 & 17.6 \\
\hline 2 & MW 2 & 0,05 & 0,25 & 1.69 & 3.622 & 15.5 \\
\hline
\end{tabular}

The method consists in keeping the sample size of 500x500 $\mathrm{mm}$ in a horizontal position in conditions where the cooling plate with a temperature of $1 \pm 0.5^{\circ} \mathrm{C}$ is adjacent to the top, the water container is located below, which the temperature is maintained at $50 \pm 1^{\circ} \mathrm{C}$.

Calculations are carried out according to the formulas.

$$
\begin{gathered}
\mathrm{W}_{\mathrm{dp}}=\frac{\mathrm{m}_{\mathrm{D}}-\mathrm{m}_{0}}{\mathrm{~A}_{\mathrm{p}}}, \\
\mathrm{W}_{\mathrm{dv}}=\frac{\mathrm{m}_{\mathrm{D}}-\mathrm{m}_{0}}{\mathrm{~A}_{\mathrm{p}} \cdot \mathrm{d}} \cdot \frac{100}{\rho_{\mathrm{W}}},
\end{gathered}
$$

$\mathrm{W}_{\mathrm{dp}}$ - amount of absorbed moisture by weight, $\mathrm{kg} / \mathrm{m}^{2}$;

$\mathrm{W}_{\mathrm{dv}}$ - amount of absorbed moisture by volume, \%;

$\mathrm{m}_{\mathrm{D}}$ - the mass of the sample after staying in the container for 28 days;

$\mathrm{m}_{0}$ - the initial mass of the sample.

Similar tests were carried out in NIISF RAASN for samples of heat-insulating material from foamed polyethylene. At the same time, two samples were tested in the device: one without a seam, the second with a connecting seam. Diffusion water absorption of polyethylene foam both with heat-reflecting coating and without it was investigated (table. $3)$. 
Table 3. The results of experimental determination of the diffusion and absorption of samples polyethylene foam.

\begin{tabular}{|c|c|c|c|c|c|c|c|c|c|}
\hline № & sample & $\begin{array}{c}\mathrm{a}, \\
\mathrm{mm}\end{array}$ & $\begin{array}{c}\mathrm{b}, \\
\mathrm{mm}\end{array}$ & $\begin{array}{c}\delta, \\
\mathrm{mm}\end{array}$ & $\begin{array}{c}\mathrm{A}, \\
\mathrm{m}^{2}\end{array}$ & $\begin{array}{c}\mathrm{m} 0, \\
\mathrm{~g}\end{array}$ & $\begin{array}{c}\mathrm{mb}, \\
\mathrm{g}\end{array}$ & $\begin{array}{c}\mathrm{W}_{\mathrm{dp}}, \\
\mathrm{kg} / \mathrm{m}^{2}\end{array}$ & $\begin{array}{c}\mathrm{W}_{\mathrm{dv}} \\
\%\end{array}$ \\
\hline & \multicolumn{8}{c|}{ Foamed polyethylene without heat-reflecting coating } \\
\hline 1 & Solid & 499,5 & 498,7 & 55,84 & 0,2491 & 222,5 & 327,3 & 0,42 & 0,71 \\
\hline 2 & $\begin{array}{c}\text { with } \\
\text { seam }\end{array}$ & 500 & 497 & 62,16 & 0,2485 & 224,4 & 334,6 & 0,44 & 0,75 \\
\hline & \multicolumn{8}{|c|}{ Foamed polyethyle with heat-reflecting coating } \\
\hline 1 & Solid & 500 & 503 & 51,07 & 0,2515 & 254,7 & 321,2 & 0,26 & 0,51 \\
\hline 2 & $\begin{array}{c}\text { with } \\
\text { seam }\end{array}$ & 502 & 508 & 52,84 & 0,2626 & 252,9 & 350,0 & 0,37 & 0,70 \\
\hline
\end{tabular}

\section{Discussion}

Research study conducted by domestic and foreign scientists, allow us to present the dependence of the thermal conductivity of the moisture content of hydrophobized mineral wool products graph shown in Fig. 3. Thus, in the range of humidity from 0 to 0.2 the thermal conductivity of the product increases by more than 4 times, which significantly reduces the thermal resistance of the structure.

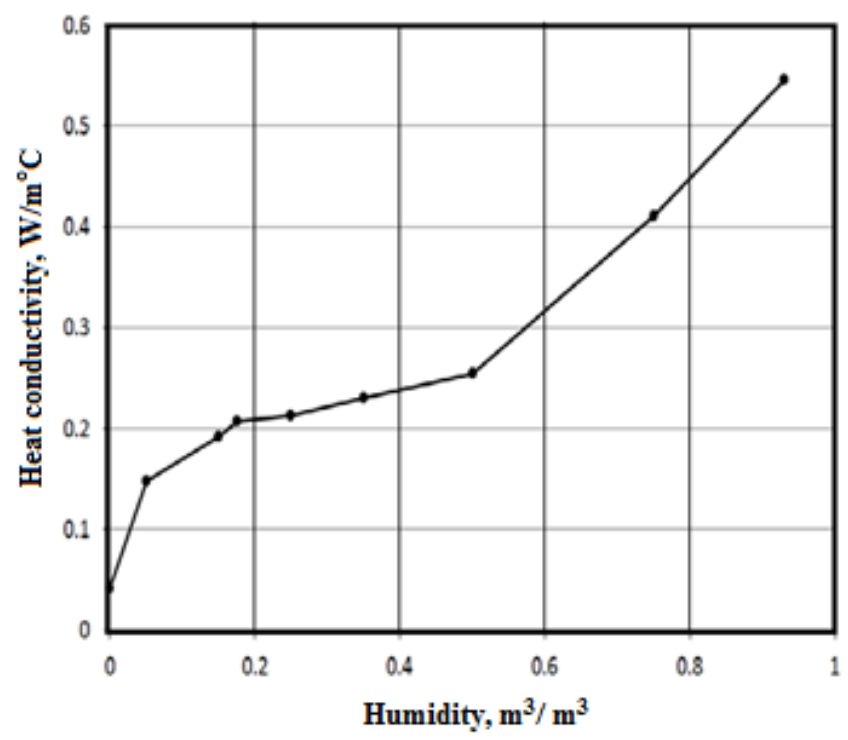

Fig. 3. Dependence of thermal conductivity of hydrophobized mineral wool products on their humidity.

The equilibrium moisture content of mineral wool products, depending on the state of the environment, the intensity of moisture exchange, the characteristics of the fibers and the porosity of the material, is in the range of $1-3 \%$, and the diffusion humidity can reach 15 $17 \%$ [16-17]. In the first case, the thermal conductivity (Fig. 3) increases to $0,08-0,10$ $\mathrm{W} /(\mathrm{m} \cdot \mathrm{K})$. Such changes occur in the insulation shell during the annual cycle of exploitation and determine the reduction of thermal resistance by 20-50\%. In the case of leaks of the roof and moisture droplets on the heat insulation, thermal resistance is reduced by 3,5-4 times. 
In case of application of soft mineral wool plates or mats there is a probability of emission of fibers of a heater (their removal) and destruction of a binding component that can lead to weakening of a heat-insulating layer and violation of its integrity. study research aimed at identifying the degree of influence of the wind flow rate of $0,5-0,9 \mathrm{~m} / \mathrm{s}$ on the thermal resistance of the insulated structure, revealed a decrease in thermal resistance by $15 \%$. To minimize mechanical emission, thermal insulation is covered with special windproof coatings: membranes, fiberglass, glass canvas.

When installing insulation formed joints, which transmit heat - that is, they become "cold bridges". Laying of thermal insulation boards is carried out in such a way as to minimize the transfer of heat through the looseness in the joints of plates or in the areas of contact of thermal insulation and load-bearing structures (for example, with rafters or with materials in the basis). Usually insulation boards are placed either with a shift by two coordinates (flat roof); or with a shift length (for pitched roof). In addition, the practice of laying the plates "back to back" in order to avoid slipping of insulation when wet or due to weathering (emission). The wooden frame, as the roofing system and the roof as a whole is subject to deformations associated with changes in the humidity of the material (as a result of changes in the moisture content of the air, the migration of the vapor-air mixture in the structure or contacts with the drip liquid (leaks)), as well as possible freezing of the wooden frame. The maximum linear shrinkage of wood products (along the length of the fibers) can be 5-6 \%. Dry wood, a long time lying in the air, has a humidity of $15-20 \%$, and in the construction, depending on the external humidity conditions, its humidity can increase to 24-30\%. Such a change in humidity corresponds to a linear deformation within $0,6-3,2 \%$.

Thus, depending on the atmospheric humidity and the penetration of droplet moisture into the construction the deformation of the wooden frame of the roof can be $0,3-1,6 \mathrm{~mm}$ per $1 \mathrm{~m}$ of the length of the element (for example, rafters). This effect eliminates the possibility of a constant tight fit of the insulation to the rafters and increase the thermal heterogeneity of the insulation system. When adhesive fixing of insulation (this includes spray-on insulation materials) it is detached from the carcass and destruction of the insulation system. Preservation of stable properties of the system and mineral wool insulation layer is achieved by the implementation of three structural methods: ventilation of the thermal insulation layer, its waterproofing (outside) and vapor barrier (inside), as well as the use of windproof materials in ventilated systems.

In the process of operation of roof structures their thermal heterogeneity is increased due to the expansion of "cold bridges" at the joints of the insulation boards on surfaces in contact with load-bearing wooden structures; also the degradation of the properties of the insulation boards first and foremost increase their thermal conductivity by increasing the humidity and shrinkage of the plates. Taking into account the whole complex of destructive processes, the thermal resistance of the insulation system in the first 5 years of operation can be reduced by 22-26\%; and make (taking into account the data table. 1, 2,7-3,1 $\mathrm{m} 2 \cdot \mathrm{oC} / \mathrm{W}$ on the surface of the roof covering or not more than $1,7 \mathrm{~m} 2 \cdot \mathrm{oC} / \mathrm{W}$, taking into account the roof glazing. Using waterproof thermal insulation materials, as well as materials with low vapor and air permeability, allows to optimize the structure of the "insulation cake" and increase the durability of the system as a whole. Similar properties have some types of foamed plastics, the use of which on a pitched roof is allowed when using truss structures and lathing of combustible materials In particular, the use of rolls of unshielded polyethylene foam (Fig. 1в) allows to obtain an insulating sheath of pitched roof without the use of additional wind protection and vapor barrier.

Foam mats (NPE) are placed between the rafters, then the entire surface on the inner side put a rolled foil polyethylene foam, which is fixed with screws with washers, and then welded with hot air along the lines of the joint. Thus, a solid insulation shell is formed, 
which does not have "cold bridges" on the surface. Next on the screws mounted the inner sheathing, which is attached to leaves the interior trim.

\section{Conclusions}

The use of rolls of polyethylene foam with a metallic coating, connected to the lock, followed by welding with hot air allows almost seamless insulating sheath. This technique eliminates heat loss through the joints of individual thermal insulation formats; allows to protect the elements of the supporting structure from the effects of cold and moisture, and to form a comfortable microclimate of the premises. Low water absorption of the material both at the level of water vapor sorption and in direct contact with the droplet liquid ensures the stability of the thermal conductivity of the material. Unstitched polyethylene foam has low air and vapor permeability, which allows to form a complex insulation shell, excluding the use of additional layers of vapor barrier and windproof materials.

The implementation of systems to protect the insulation of the building envelope aimed at creation of comfortable conditions in the room; to decrease the energy and material inputs at operations of buildings; preservation of properties of building elements and increase the longevity of roof structures. These conditions are met as a result of the following construction tasks: minimizing heat loss through the insulated perimeter of the building; excluding moisture penetration into the building structure and the room, as well as ensuring the removal of excess moisture naturally.

\section{References}

1. I.J. Gnip, V.J. Keršulis, S.J. Vaitkus Mechanics of Composite materials 41, 357-364 (2005)

2. I.V. Bessonov, A.V. Starostin, V.M. Oskin, Vestnik MGSU 3(2), 1334-139 (2011)

3. B. Rumiantcev, A. Zhukov, E. Bobrova, I. Romanova, D. Zelenshikov, T. Smirnova, MATEC Web of Conf. 86 (2016)

4. D. Zhukov, K.A. Ter-Zakaryan, V.S. Semenov, ScienceDirect IFAC Paper 51(30), 803-807 (2018)

5. A.D. Zhukov, T.V. Konoval'tseva, E.Yu. Bobrova, E.A. Zinovieva, K.K. Ivanov, MATEC Web of Conf. 251 (2018)

6. A.D. Zhukov, K.A. Ter-Zakaryan, V.S. Semenov, S.D. Kozlov, E.A. Zinovieva, E.D. Fomina, MATEC Web of Conf. 251 (2018)

7. B. Rumiantcev, A. Zhukov, D. Zelenshikov, A. Chkunin, K. Ivanov, Y. Sazonova, MATEC Web of Conf. 86 (2016)

8. A. Medvedev, E. Bobrova, A. Poserenin, E. Zarmanyan, MATEC Web of Conferences 170 (2018)

9. M. Asamatdinov, A. Medvedev, A. Zhukov, E. Zarmanyan, A. Poserenin, MATEC Web of Conferences 193 (2018)

10. E. Pyataev, A. Medvedev, A. Poserenin, M. Burtseva, E. Mednikova, V. Mukhametzyanov, MATEC Web of Conferences 251 (2018)

11. V.G. Gagarin, V.V. Kozlov, Academia. Architecture and buildments 2, 60-63 (2006)

12. N.I. Vatin, I.I. Pestryakov, Sh.T. Sultanov, T.O. Ogidan, Y.A. Yarunicheva, A.P. Kiryushina, Magazine of Civil Engineering 81, 183-192 (2018) 
13. A.D. Zhukov, K.A. Ter-Zakaryan, A.V. Zayafarov, Ye.S. Petrovsky, D.U. Tuchaev, Roofing and insulation materials 6, 27-29 (2017)

14. H. Zhuk, A. Zhukov, Ecology and industry of Russia 4, 52-57 (2018)

15. A. Gnip, S. Vaitkus, V. Kersulis, S. Vejelis, Mech Time Depend Mater 16, 31-46 (2012) 